
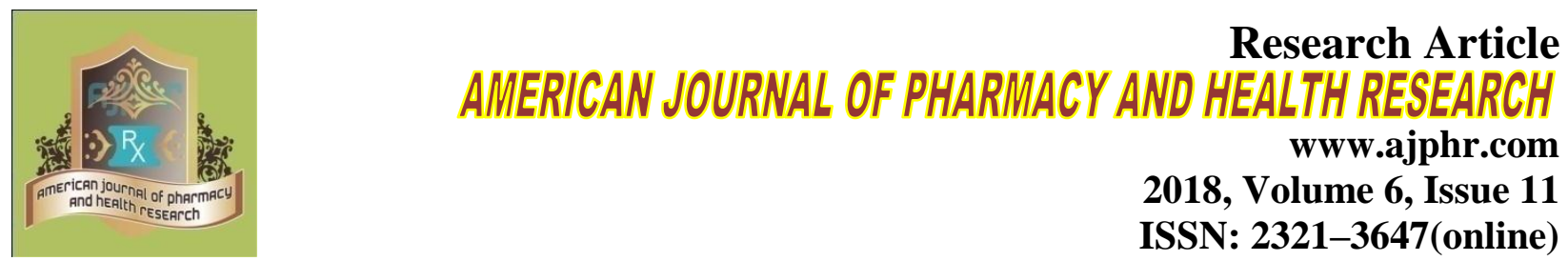

2018, Volume 6, Issue 11

ISSN: 2321-3647(online)

\title{
Formulation and Evaluation of Aloe Vera Gel and Film From Fresh Pulp of the Leaves of Aloe Barbadensis
}

\author{
Tirupati Rasala*, Shivani Dani, Shekhar Waikar, Abhay Ittadwar.
}

Gurunanak College of Pharmacy, Dixit Nagar, Behind CP Foundary, Nari, Nagpur-440026

\begin{abstract}
The historians have recorded many applications of aloe species both in the medical field as well as in cosmetics. It is used to heal burns, to prevent blisters for the treatment of wounds and in various kinds of damaged skin. Burns are serious traumas related to skin damage, causing extreme pain and natural drugs such as Aloe vera is beneficial in formulations for wound healing. The aim of this work is to develop and evaluate polymeric films containing Aloe Vera crude extracts to smoothen and treat minor wounds caused by burns. Polymeric films containing different quantities of HPMC and polyvinyl alcohol (PVA) were characterized for their mechanical properties. The polymeric films, which were formulated, were found to be thin, flexible, resistant, and suitable for application on damaged skin, such as in burns \& wounds. The formulated gel was evaluated for evaluations parameters were thickness, tensile strength and water vapour permeability. general appearance, homogeneity, $\mathrm{pH}$, spreadability test, washed test and skin irritation test. Film
\end{abstract}

Keywords: Aloe Vera, Gel and Film. 


\section{INTRODUCTION}

\section{Objective}

The aim of this work is to develop and evaluate polymeric films containing Aloe Vera crude extract to soothen and treat minor wounds caused by burns. Polymeric films containing different quantities of HPMC and polyvinyl alcohol (PVA) were characterized for their mechanical properties. The polymeric films, which were formulated, were found to be thin, flexible, resistant, and suitable for application on damaged skin, such as in burns \& wounds. The formulated gel was evaluated for general appearance, homogeneity, $\mathrm{pH}$, spreadability test, washed test and skin irritation test. Film evaluations parameters were thickness, tensile strength and water vapour permeability.

\section{Plant Profile}

\section{Synonym:}

Aloe, Musabbar, Kumari

\section{Biological source:}

Aloes is the dried juice of the leaves of Aloe barbadensis Miller, known as Cracao aloes; or of Aloe perryi Baker, known as Socotrine aloes; or of Aloe ferox Miller and hybrids of this species with Aloe Africana Miller and Aloe spicata Baker, known as Cape aloes, belonging to family Liliaceaceae depicted in figure 1.

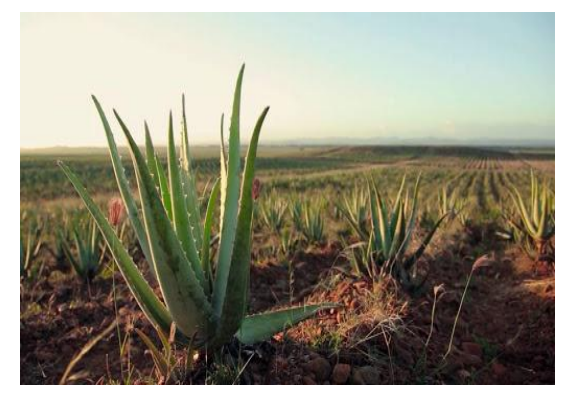

Figure: 1 Aloe barbadensis leaf

\section{Geographical source:}

Aloes is Indigenous to eastern and southern Africa and grown In Cape colony, Zanzibar and island of Soctra. It is also cultivated in Caribbean island, Europe and many parts of India, including North West Himalayan region.

\section{Chemical constituents:}

The most important constituents of aloes are the three isomers of aloins, barbaloin, betabarbaloin and isobarbaloin, which constitute so-called crystalline aloin, present in the drug at from 10 to $30 \%$. Other constituents are amorphous aloin, resin, emodin and aloe emodin. The drug also 
contains aloetic acid, homonataloin, choline salicylate, choline, saponins, aloesone chrysaophanic acid, chrysamminic acid, mucopolysaccharides, hexuronic acid, coniferyl alcohol etc.

\section{Medicinal uses:}

1. Stimulating and purgative. 2. In higher doses may act as an abortifacie and vermifuge. 3. The plant is emmenagogue, emollient, stomachic and tonic. 4. Extract of plant has antibacterial activity. 5. The clear gel of leaf makes an excellent treatment of Wounds, Burns and other skin disorder, placing the protective coat over the affected area. 6. It is also used in treatment of pains and itching and also slows down ulceration and keratosis. 7. Aloes used externally for painful inflammation.

\section{Rationale}

1. The survey literature has revealed that a very meager amount of data is available as far as the Pharmacological evaluation of this plant.

2. Many herbal formulations contain the processed extract of medicinal plants. Isolation of specific phytoconstituents from these crude extract enables us to achieve enhanced activity.

3. Therefore it was though worthwhile to carry out research work on Aloe barbadensis leaf and to formulate aloe gel \& film and to evaluate its physicochemical properties.

\section{MATERIALS AND METHOD}

Aloe vera leaves were collected from Pharmacognosy Garden of Gurunanak College of Pharmacy, Nari, Nagpur. The gel is prepared by peeling the outer portion of skin and pericarp. The exudate which is voluntarily removing from leaf is collected and used freshly within 4 hrs. The chemicals used are HPMC (GRM2257_500G), PEG, Methyl paraben. 
Table 1 Formulation and development of Aloe vera gel and film formulation

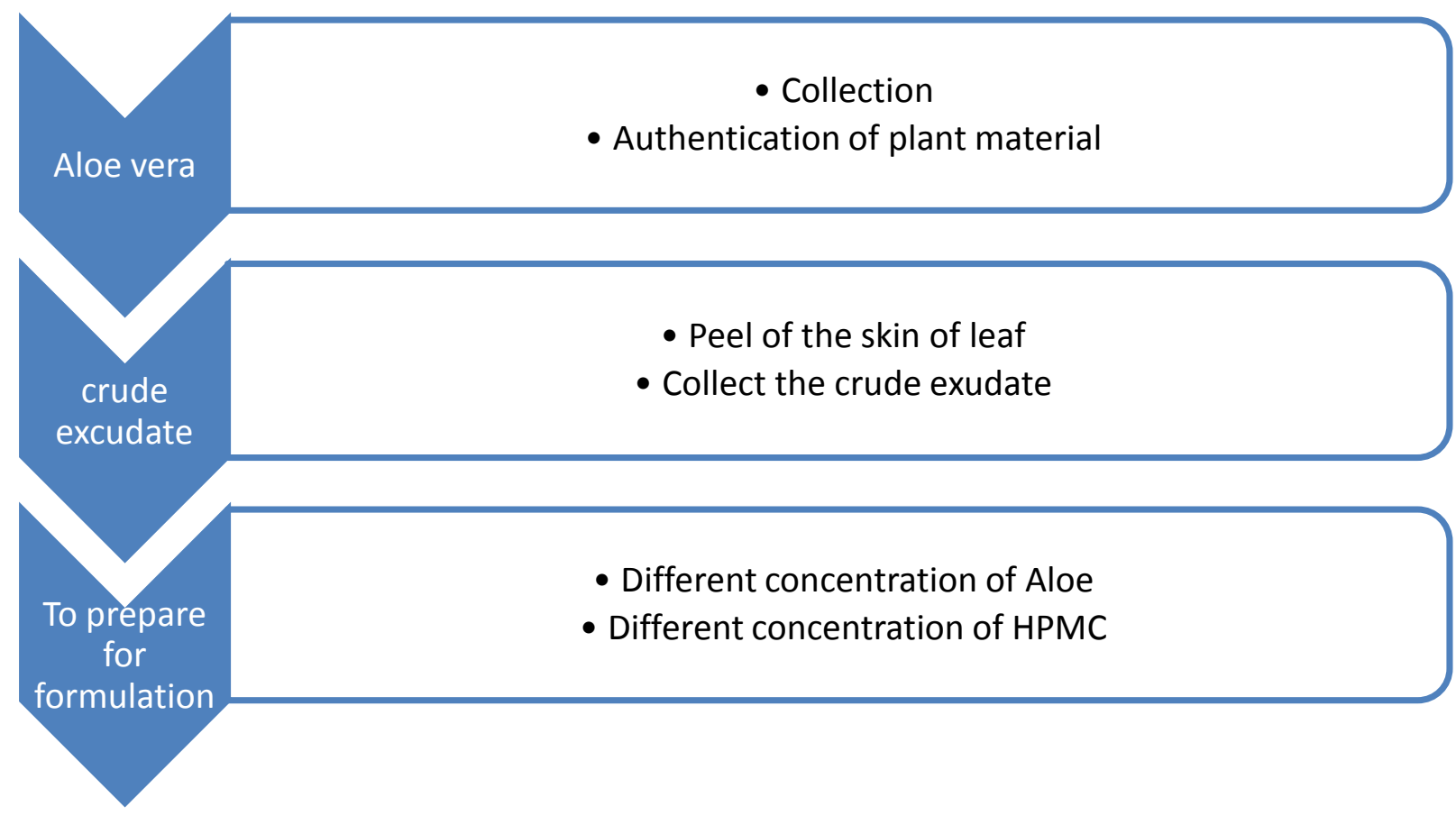

\section{Formulation of Aloe vera gel}

The formulation of Aloe vera gel with different concentrations (5\%, \& 10\%) of Aloe vera, HPMC (GRM2257-500G) with different concentrations (3\%, 4\%, and 5\%) with both of 5\% and $10 \%$ of aloe vera crude concentration, was prepared. The aloe exudates was obtained and is taken in a beaker in above mentioned concentrations, $10 \mathrm{ml}$ of water is added in it. The exudates were dissolved and little warmed it. The different concentrations of HPMC were dissolved in small portions by mechanical stirring and gently heating. Remaining ingredients were added like preservatives and PEG and the gel is formulated. The Formulation development of Aloe Vera gel \& Film was depicted in Table no.2

Table 2: Formulation development of Aloe Vera gel \& Film

\begin{tabular}{lllllll}
\hline Ingredient & $\mathbf{F}_{\mathbf{1}}$ & $\mathbf{F}_{\mathbf{2}}$ & $\mathbf{F}_{\mathbf{3}}$ & $\mathbf{F}_{\mathbf{4}}$ & $\mathbf{F} \mathbf{5}$ & $\mathbf{F}_{\mathbf{6}}$ \\
\hline Aloe vera exudates (\%) & 5 & 10 & 5 & 10 & 5 & 10 \\
HPMC (\% & 3 & 3 & 4 & 4 & 5 & 5 \\
PEG (\%) & 5 & 10 & 5 & 10 & 5 & 10 \\
Methyl paraben (\%) & 0.1 & 0.1 & 0.1 & 0.1 & 0.1 & 0.1 \\
Distilled water(QC) & 100 & 100 & 100 & 100 & 100 & 100 \\
\hline
\end{tabular}




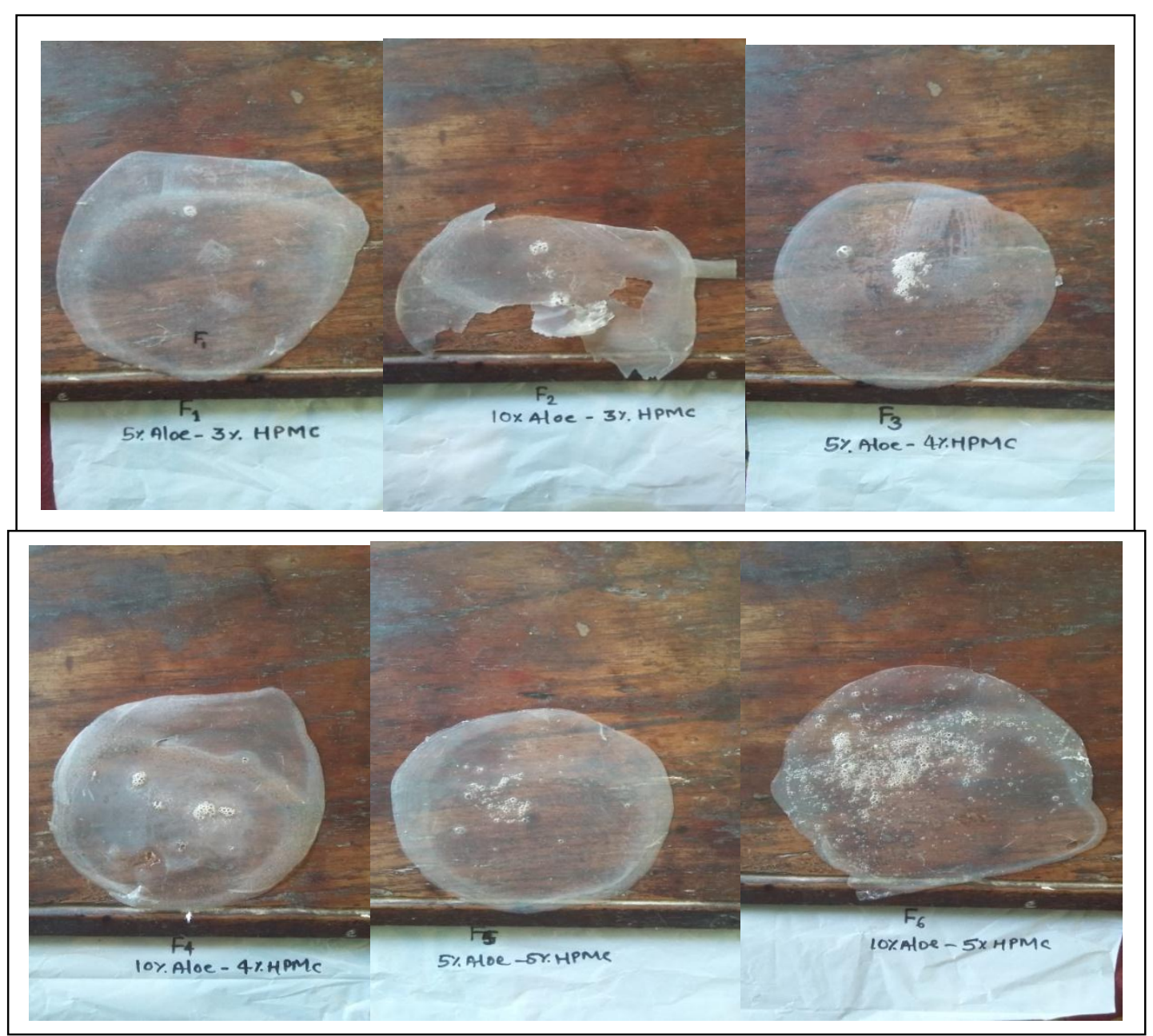

Figure 2: Aloe vera film formulations at various concentrations

\section{EVALUATION}

All formulations were evaluated for:

1. Colour

2. Odour

3. Transparency

4. Consistency

5. Spreadability

6. $\mathrm{pH}$

7. Skin irritability

8. Water vapour transmission

9. Moisture absorbance

10. Folding endurance

11. Thickness 
12. Film appearance

\section{Evaluation of Aloe vera gel}

\section{Transparency, smoothness and weight on drying}

The $5 \mathrm{ml}$ gel formulation taken in the $10 \mathrm{ml}$ (Borosil ${ }^{\mathrm{R}}$ ) test tube and visually checked for its transparency. The smoothness of the gel formulation was tested by rubbing between the fingers and observes whether the gel is smooth, clumped, homogenous or rough. The relative density of the formulation or weight $/ \mathrm{ml}$ of the formulation was determined by taking the weight in gm of

\section{Evaluation of Aloe vera film:}

\section{Percentage Moisture Absorbed}

Films were cutted in $2 \times 2 \mathrm{~cm}^{3}$. The desiccator was saturated with saturated $\mathrm{NaCl}$ solution by filling it in a porcelain dish keeping it in a desiccators and leaving it for $24 \mathrm{hrs}$. The films were kept in desiccators for next $24 \mathrm{hrs}$ after taking initial weight. After $24 \mathrm{hrs}$ the films were reweighed and calculated as:

$$
\% \text { Moisture content }=\text { Final wt. }- \text { Initial wt. } / \text { Initial wt. } \times 100
$$

\section{Skin irritation test}

No irritation was occurred when applied on skin.

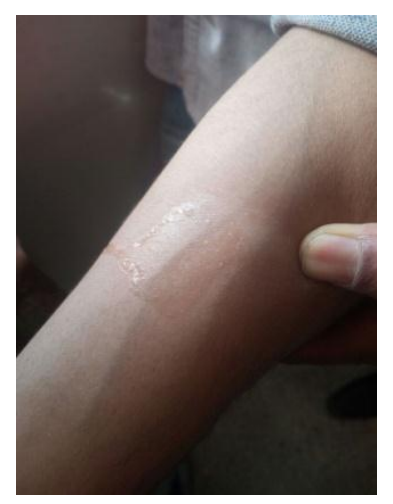

\section{Percentage Water vapour transmission}

Films were cutted in $2 \times 2 \mathrm{~cm}^{3}$. The saturated $\mathrm{NaCl}$ solution by filling it in weighing bottles. The films were kept on weighing bottles for next $24 \mathrm{hrs}$ after taking initial weight. After $24 \mathrm{hrs}$ the films were reweighed and calculated as:

$$
\% \text { Moisture content }=\frac{\text { Initial wt. }- \text { Final wt }}{\text { Final wt. }} \times 100
$$

\section{Folding endurance for film:}

The film was folded until it was teared. The Folds required to break the film was noted and the time required to tear the film was noted when the film was not teared. 


\section{RESULTS AND DISCUSSION}

Table 3: Clarity of aloe vera gel

\begin{tabular}{lllllll}
\hline Aloe vera gel & $\mathbf{F}_{1}$ & $\mathbf{F}_{2}$ & $\mathbf{F}_{3}$ & $\mathbf{F}_{4}$ & $\mathbf{F}_{5}$ & $\mathbf{F}_{6}$ \\
\hline Exudates+Water+ & Opaque & Opaque & transparent & opaque & transparent & Opaque \\
HPMC+PEG+Methyl paraben & & & & & & \\
\hline
\end{tabular}

Table 4: Odour of aloe vera gel

\begin{tabular}{lllllll}
\hline Aloe vera gel & $\mathbf{F}_{\mathbf{1}}$ & $\mathbf{F}_{\mathbf{2}}$ & $\mathbf{F}_{\mathbf{3}}$ & $\mathbf{F}_{\mathbf{4}}$ & $\mathbf{F}_{\mathbf{5}}$ & $\mathbf{F}_{\mathbf{6}}$ \\
\hline Exudates+Water+ & specific & specific & specific of & specific & specific & specific \\
HPMC+PEG+Methyl paraben & of aloe & of aloe & aloe & of aloe & of aloe & of aloe \\
\hline
\end{tabular}

Table 5: Spreadability of aloe vera gel

\begin{tabular}{lllllll}
\hline Aloe vera gel & F1 $_{1}$ & $\mathbf{F}_{2}$ & $\mathbf{F}_{3}$ & $\mathbf{F}_{4}$ & $\mathbf{F}_{5}$ & $\mathbf{F}_{\mathbf{6}}$ \\
\hline Exudates+Water+ & Excellent & Excellent & Excellent & Excellent & Poor & Poor \\
HPMC+PEG+Methyl paraben & & & & & & \\
\hline
\end{tabular}

Table 6: Consistency of aloe vera gel

\begin{tabular}{lllllll}
\hline Aloe vera gel & $\mathbf{F}_{1}$ & $\mathbf{F}_{2}$ & $\mathbf{F}_{3}$ & $\mathbf{F}_{4}$ & $\mathbf{F}_{5}$ & $\mathbf{F}_{6}$ \\
\hline Exudates+Water+ & Thin & Thin & Thin & Thin & Thick & Thick \\
HPMC+PEG+Methyl paraben & & & & & & \\
\hline
\end{tabular}

Table 7: Percentage water Vapor Transmission of aloe vera Film

\begin{tabular}{lcccccc}
\hline Aloe vera Film & F1 $_{1}$ & $\mathbf{F}_{\mathbf{2}}$ & $\mathbf{F}_{\mathbf{3}}$ & $\mathbf{F}_{\mathbf{4}}$ & $\mathbf{F}_{\mathbf{5}}$ & $\mathbf{F}_{\mathbf{6}}$ \\
\hline Exudates+ Water+ & 00 & 00 & 00 & 00 & 00 & 00 \\
HPMC+PEG+Methyl paraben & & & & & & \\
\hline
\end{tabular}

Table 8: \% Percentage moisture Absorbance of aloe vera Film

\begin{tabular}{lllllll}
\hline Aloe vera gel & $\mathbf{F}_{\mathbf{1}}$ & $\mathbf{F}_{\mathbf{2}}$ & $\mathbf{F}_{\mathbf{3}}$ & $\mathbf{F}_{\mathbf{4}}$ & $\mathbf{F}_{\mathbf{5}}$ & $\mathbf{F}_{\mathbf{6}}$ \\
\hline Exudates+ Water+ & 00 & $12.5 \%$ & 00 & 00 & $12 . .5 \%$ & $7.14 \%$ \\
HPMC+PEG+Methyl paraben & & & & & & \\
\hline
\end{tabular}

Table 9: Folding Endurance of Aloe Vera film

\begin{tabular}{lllllll}
\hline Aloe vera Film & F1 $_{1}$ & $\mathbf{F}_{\mathbf{2}}$ & $\mathbf{F}_{3}$ & $\mathbf{F}_{\mathbf{4}}$ & $\mathbf{F}_{\mathbf{5}}$ & $\mathbf{F}_{\mathbf{6}}$ \\
\hline Time $(\mathrm{Sec})$ & $39 \mathrm{sec}$ & $60 \mathrm{sec}$ & $33 \mathrm{sec}$ & $10 \mathrm{sec}$ & $15 \mathrm{sec}$ & $19 \mathrm{sec}$ \\
Folds & 23 & 45 & 19 & 3 & 7 & 11 \\
\hline
\end{tabular}

The Aloe vera gel and film were formulated and evaluated for various parameters mentioned above and the best film was selected on the basis of the concentration of aloe vera exudates, HPMC.

\section{CONCLUTION}

On the basis of various observations we concluded that the film namely $F_{1}, F_{3}, F_{4}, F_{5}$ showed 
excellent film forming properties with smoothening effect. Regular use of this gel surely show wrinkles free tightened skin.

\begin{tabular}{lllll}
\hline Film & F1 $_{1}$ & $\mathbf{F}_{\mathbf{3}}$ & $\mathbf{F}_{\mathbf{4}}$ & $\mathbf{F}_{\mathbf{5}}$ \\
\hline Aloe vera & $5 \%$ & $5 \%$ & $10 \%$ & $5 \%$ \\
HPMC & $3 \%$ & $4 \%$ & $4 \%$ & $5 \%$ \\
Result & Excellent & Good & Excellent & Better \\
\hline
\end{tabular}

\section{ACKNOWLEDGEMENT}

The authors wish to thank management of Sikh education society and Principal Dr. A. M. Iattadwar Gurunanak College of pharmacy, Nagpur for providing necessary facilities to carry out the work.

\section{REFERENCES}

1. Aloe vera a systematic review of its clinical effectiveness Vogler BK, Ernst E ". The British journal of general practice: the journal of the Royal College of General Practitioners 1999; 49:823-8

2. Rajendran A, Narayanan V, Gnanavel I Photochemical and Electrochemical Stabilities of Aloe Vera Sap Journal of Applied Sciences Research, 2007; 3:1871-1878.

3. Eshu K, He Q "Aloe vera: a valuable ingredient for the food, pharmaceutical and cosmetic industries--a review". Critical reviews in food science and nutrition 2004; 44:91-96.

4. Amar S, Resham V, Saple DG Aloe Vera: A short review. Indian J Dermato 2008; 53:163-166.

5. Plant Remedies Aloe Vera www.internethealthlibrary.com, downloaded on August 4, 2010.

6. Gupta Udit, Omray LK, PatilS, Kharya AK, Gajbhiye A, Chaturvedi S, Agrawal GP Development of aloe vera cosmetic herbal hydrogel formulation, International Herbal Conference 2009.

7. Udupa S.I., Udupa A.L., Kulakrni D.R. Anti-inflammatory and wound healing properties of Aloe vera, Fitotherapia, 1994, 65: 141-145.

8. Mihalovits, Donna M. Cosmetic facial preparation containing aloe vera, United States Patent no. 4369180, date 18/01/1983.

9. Devi KV, Saisivam S, Maria GR, Deepti PU Design and evaluation of matrix diffusion controlled transdermal patches of verapamil hydrochloride. Drug Deve Ind Pharm 2003; 29:495-503. 
10. Dheepika B, Uma Maheswari T.N. Aloe Vera in Oral Diseases-A Review; International Journal of Pharmacy and Pharmaceutical Sciences Vol 6, Suppl 2, 2014.

AJPHR is

Peer-reviewed

monthly

Rapid publication

Submit your next manuscript at

editor@ajphr.com / editor.ajphr@gmail.com 